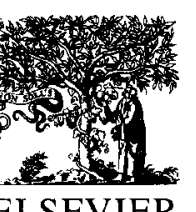

International Journal of Mass Spectrometry and Ion Processes 151 (1995) 63-68

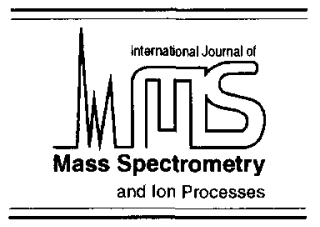

\title{
Quantification of impurities in brass using secondary ion mass spectrometry: a comparison of matrix effects for $\mathrm{CsM}^{+}$clusters and $\mathrm{M}^{+}$ions
}

\author{
A. Adriaens, C. Férauge, F. Adams \\ University of Antwerp, Department of Chemistry, Universiteitsplein 1, 2610 Wilrijk, Belgium
}

Received 26 April 1995; accepted in final form 21 July 1995

\begin{abstract}
This study discusses the influence of matrix effects on relative sensitivity factors in secondary ion mass spectrometry for a quantification study of major and impurity elements in standard brass reference materials. A comparison has been made between relative sensitivity factors, which are obtained through acquisition of $\mathrm{CsM}^{+}$clusters under cesium bombardment and of $\mathrm{M}^{+}$ions under oxygen bombardment. The data of the present study suggest that the matrix effects have been reduced in the case of cesium clusters, but nevertheless remain significant. In addition, the reproducibility for determining relative sensitivity factors improves significantly for cesium clusters.
\end{abstract}

Keywords: Cesium clusters; Matrix effect; Quantification; Relative sensitivity factors; Secondary ion mass spectrometry

\section{Introduction}

It has been demonstrated in several studies that quantitative applications in secondary ion mass spectrometry are primarily limited by theoretical or physical models for converting ion intensity data into elemental concentrations [1,2]. This is primarily due to the fact that the ionization probability is not only element sensitive, but it also depends upon the composition of the sample. Variations in the concentration of matrix elements can therefore affect the secondary ion yield of those same elements, which makes quantitative procedures difficult.

\footnotetext{
* Corresponding author.
}

These problems are more likely to be reduced by sampling the sputtered neutrals above the sample surface and generating the secondary ions by post-ionization, reducing so-called matrix effects $[3,4]$.

In the past, it has been demonstrated that bombardment by $\mathrm{Cs}^{+}$ions can be used as a means of post-ionization in secondary ion mass spectrometry [4-7]. Experiments have indicated that the formation of $\mathrm{CsM}^{+}$clusters occurs by recombination of $\mathrm{Cs}^{+}$ions and sputtered neutral sample atoms above the sample surface, which implies that the sputter and ionization processes have become two independent phenomena $[5,6]$.

Reduced matrix effects in the case of $\mathrm{CsM}^{+}$ clusters have primarily been observed in the 
Table 1

Composition of the standard reference materials (in at. $\mathrm{wt} \%$ )

\begin{tabular}{|c|c|c|c|c|c|}
\hline \multirow[t]{2}{*}{ Element } & \multicolumn{5}{|l|}{ Sample } \\
\hline & SRM1106 & SRM1103 & SRM1107 & SRM 1115 & SRM 1108 \\
\hline $\mathrm{Cu}$ & 60.017 & 61.714 & 62.316 & 88.283 & 65.792 \\
\hline $\mathrm{Zn}$ & 39.533 & 36.116 & 36.91 & 11.431 & 33.854 \\
\hline $\mathrm{Fe}$ & 0.005 & 0.308 & 0.043 & 0.148 & 0.058 \\
\hline Sn & 0.402 & 0.491 & 0.566 & 0.054 & 0.211 \\
\hline $\mathrm{Ni}$ & 0.027 & 0.18 & 0.108 & 0.08 & 0.036 \\
\hline
\end{tabular}

literature for III-V compound semiconductors $[4,8,9]$. In this paper it is the intention to study and compare the results of a quantification procedure for $\mathrm{CsM}^{+}$clusters and $\mathrm{M}^{+}$ions in standard brass alloys. The relative sensitivity factor quantification method has been used in this study for the conversion of ion currents into concentrations. It makes lise of the intensity of the species of interest $\left(I_{x}\right)$ and the intensity of a reference species $\left(I_{r}\right)$, whereby the ratio of the two is used to calculate the concentration. The conversion factor between the intensity ratio and the concentration ratio is the so-called relative sensitivity factor (RSF), determined by the analysis of a similar standard reference material with known concentrations:

$\mathrm{RSF}=\frac{I_{x}}{I_{r}} \frac{c_{r}}{c_{x}} \frac{A_{r}}{A_{x}}$

where $I$ is the peak intensity, $c$ the concentration in atomic percent and $A$ the isotopic abundance. The subscripts $x$ and $r$ refer to the element of interest and the reference element, respectively.

The influence of matrix effects upon the relative sensitivity factors has been discussed in the present study for the acquisition of $\mathrm{CsM}^{+}$clusters under cesium bombardment and $\mathrm{M}^{+}$ions under oxygen bombardment.

\section{Experiment}

Standard reference brass material (SRM) samples were used in the current quantification analyses. A total of five alloys with different compositions were examined, for which both matrix and impurity elements were analyzed. Table 1 lists the analyzed elements with their concentration (at. wt. \%) for each of the standard materials used.

The analyses were performed with a Cameca IMS $4 \mathrm{f}$ ion microanalyzer. For the acquisition of the $\mathrm{CsM}^{+}$clusters, a cesium ion beam with a net energy of $5.5 \mathrm{keV}$ and an intensity of $150 \mathrm{nA}$ was used to bombard the samples. For the other set of analyses, in which $\mathbf{M}^{+}$ ions were determined, an $\mathrm{O}_{2}^{+}$beam was used with a net energy of $8.5 \mathrm{keV}$ and an intensity of $150 \mathrm{nA}$. For each analysis an area $250 \mu \mathrm{m}$ in diameter was analyzed in order to reduce potential heterogeneity effects of the samples.

The relative sensitivity factors were determined according to Eq. (1). The intensity of ${ }^{65} \mathrm{Cu}^{+}$(or $\mathrm{Cs}^{65} \mathrm{Cu}_{2}^{+}$in the case of $\mathrm{Cs}^{+}$bombardment) was taken as a reference $\left(I_{r}\right) . I_{x} / I_{r}$ was determined by measuring $I_{x}$ and $I_{r}$ over 25 cycles, and averaging the ratio. In the case of oxygen bombardment, $I_{x}$ refers to the intensities for ${ }^{70} \mathrm{Zn}^{+}$(matrix elements), ${ }^{56} \mathrm{Fe}^{+}$, ${ }^{120} \mathrm{Sn}^{+}$and ${ }^{60} \mathrm{Ni}^{+}$(impurity element). For cesium bombardment, $I_{x}$ refers to the intensities of $\mathrm{Cs}^{70} \mathrm{Zn}^{+}, \mathrm{Cs}^{56} \mathrm{Fe}^{+}, \mathrm{Cs}^{116} \mathrm{Sn}^{+}$and $\mathrm{Cs}^{60} \mathrm{Ni}^{+}$. The measured isotopes of each element were chosen to have minimal influence of potential interferences. At the same time, the isotopic ratio ${ }^{63} \mathrm{Cu}^{+} /{ }^{65} \mathrm{Cu}^{+}$ $\left(\mathrm{Cs}^{63} \mathrm{Cu}_{2}^{+} / \mathrm{Cs}^{65} \mathrm{Cu}_{2}^{+}\right.$for $\mathrm{Cs}^{+}$bombardment) was measured to monitor potential anomalies 
Table 2

Average elemental sensitivity factors for $\mathrm{Fe}, \mathrm{Ni}, \mathrm{Sn}$ and $\mathrm{Zn}$ relative to $\mathrm{Cu}$ in brass

\begin{tabular}{|c|c|c|c|c|c|c|}
\hline \multirow[t]{2}{*}{ Element } & \multirow[t]{2}{*}{ Condition } & \multicolumn{5}{|l|}{ Sample } \\
\hline & & SRM 1106 & SRM 1103 & SRM 1107 & SRM 1115 & SRM 1108 \\
\hline $\mathrm{Fe}$ & $\mathrm{Cs}^{+}$ & $106 \pm 19$ & $48 \pm 19$ & $75 \pm 11$ & $82 \pm 15$ & $85 \pm 32$ \\
\hline $\mathrm{Fe}$ & $\mathrm{O}_{2}^{+}$ & $776 \pm 1142$ & $9 \pm 2$ & $51 \pm 62$ & $25 \pm 11$ & $28 \pm 27$ \\
\hline $\mathrm{Ni}$ & $\mathrm{Cs}^{+}$ & $31 \pm 4$ & $24 \pm 9$ & $24 \pm 4$ & $36 \pm 2$ & $40 \pm 12$ \\
\hline $\mathrm{Ni}$ & $\mathrm{O}_{2}^{+}$ & $20 \pm 25$ & $2.6 \pm 0.2$ & $4 \pm 2$ & $5 \pm 3$ & $6 \pm 4$ \\
\hline $\mathrm{Sn}$ & $\mathrm{Cs}^{+}$ & $17 \pm 6$ & $36 \pm 23$ & $30 \pm 9$ & $33 \pm 3$ & $38 \pm 25$ \\
\hline $\mathrm{Sn}$ & $\mathrm{O}_{2}^{+}$ & $52 \pm 69$ & $2.2 \pm 0.4$ & $11 \pm 14$ & $27 \pm 36$ & $3.2 \pm 1.3$ \\
\hline $\mathrm{Zn}$ & $\mathrm{Cs}^{+}$ & $85 \pm 6$ & $101 \pm 24$ & $92 \pm 10$ & $108 \pm 8$ & $104 \pm 27$ \\
\hline $\mathrm{Zn}$ & $\mathrm{O}_{2}^{+}$ & $0.33 \pm 0.18$ & $0.23 \pm 0.03$ & $0.30 \pm 0.13$ & $0.47 \pm 0.23$ & $0.27 \pm 0.10$ \\
\hline
\end{tabular}

The uncertainties given are equal to one standard deviation.

during each analysis. The analyses were run at low mass resolution.

The entire study consisted of two sets of experiments, the results of which were compared with each other. The experiments differed in their means of ionization (cesium or oxygen) and the acquisition of secondary species $\left(\mathrm{CsM}^{+}\right.$or $\left.\mathrm{M}^{+}\right)$. The designs of the two experiments were identical to each other. Each individual experiment was subdivided into three sessions, in which the relative sensitivity factors for the four elements ( $\mathrm{Fe}, \mathrm{Ni}, \mathrm{Sn}$ and $\mathrm{Zn}$ ) were determined in all five standard reference materials. Each separate session consisted of three repeat analyses. The sessions were performed on different days, and the instrumental parameters were kept the same between sessions. This means that for each individual element a total of 45 values for the sensitivity factor (five samples, three sessions and three repeat analyses) were determined in each of the two experiments.

\section{Results and discussion}

Table 2 lists the average elemental sensitivity factors relative to copper for the four elements analyzed, for both the cesium and the oxygen measurements. The results show that the reproducibility is quite low, in particular for the oxygen analyses $\left(\mathrm{M}^{+}\right.$acquisition). It ranges between 6 and $147 \%$ for oxygen measurements and 6 and $65 \%$ for cesium measurements. Part of the variation observed within an SRM group may be due to heterogeneities in the sample. It is, however, assumed that this is not the main source of variation, partly because the reproducibilities for cesium and oxygen measurements differ considerably from each other. In addition, the absolute RSF values obtained by cesium and oxygen measurements differ from each other for the same element. This is to be expected, however, owing to the different ionization schemes.

Table 3 lists the total relative variation (variance divided by the square of the mean of all 45 values) for each element and analysis condition and again demonstrates the difference in reproducibility for the two measurement conditions. In order to test whether the overall variability in relative sensitivity factors has been significantly reduced in the case of cesium analyses, an $F$-test is performed [10]. As shown in Table 3, the ratio of the relative variances $\sigma_{\mathrm{R}}^{2}\left(\mathrm{O}_{2}^{+}\right) / \sigma_{\mathrm{R}}^{2}\left(\mathrm{Cs}^{+}\right)$for the three

Table 3

Total relative variance $(\%)$ for each analysis set

\begin{tabular}{lrrrr}
\hline & \multicolumn{1}{c}{$\mathrm{Fe}$} & $\mathrm{Ni}$ & $\mathrm{Sn}$ & $\mathrm{Zn}$ \\
\hline Oxygen & 10.44 & 2.71 & 4.20 & 0.27 \\
Cesium & 0.11 & 0.31 & 0.30 & 0.19 \\
Ratio $\left(\mathrm{O}_{2} / \mathrm{Cs}\right)$ & 94.90 & 8.74 & 14.00 & 1.42 \\
\hline
\end{tabular}




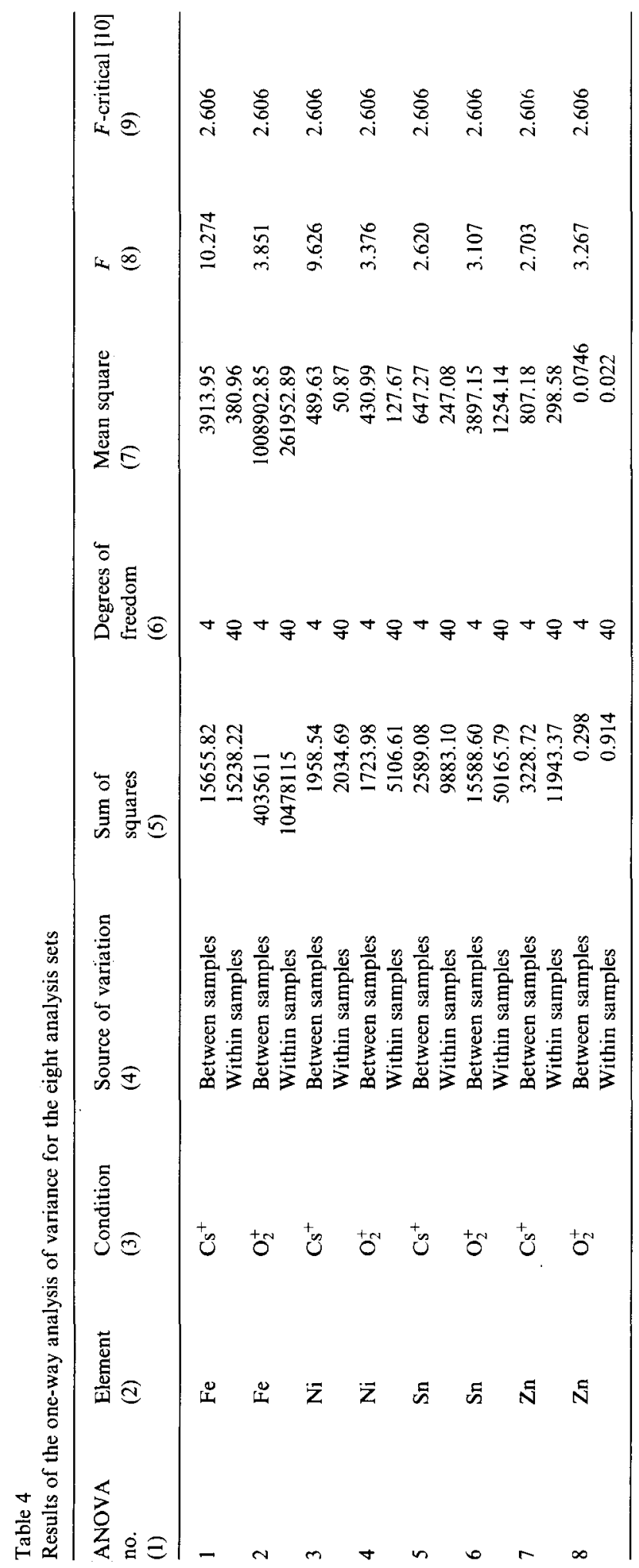




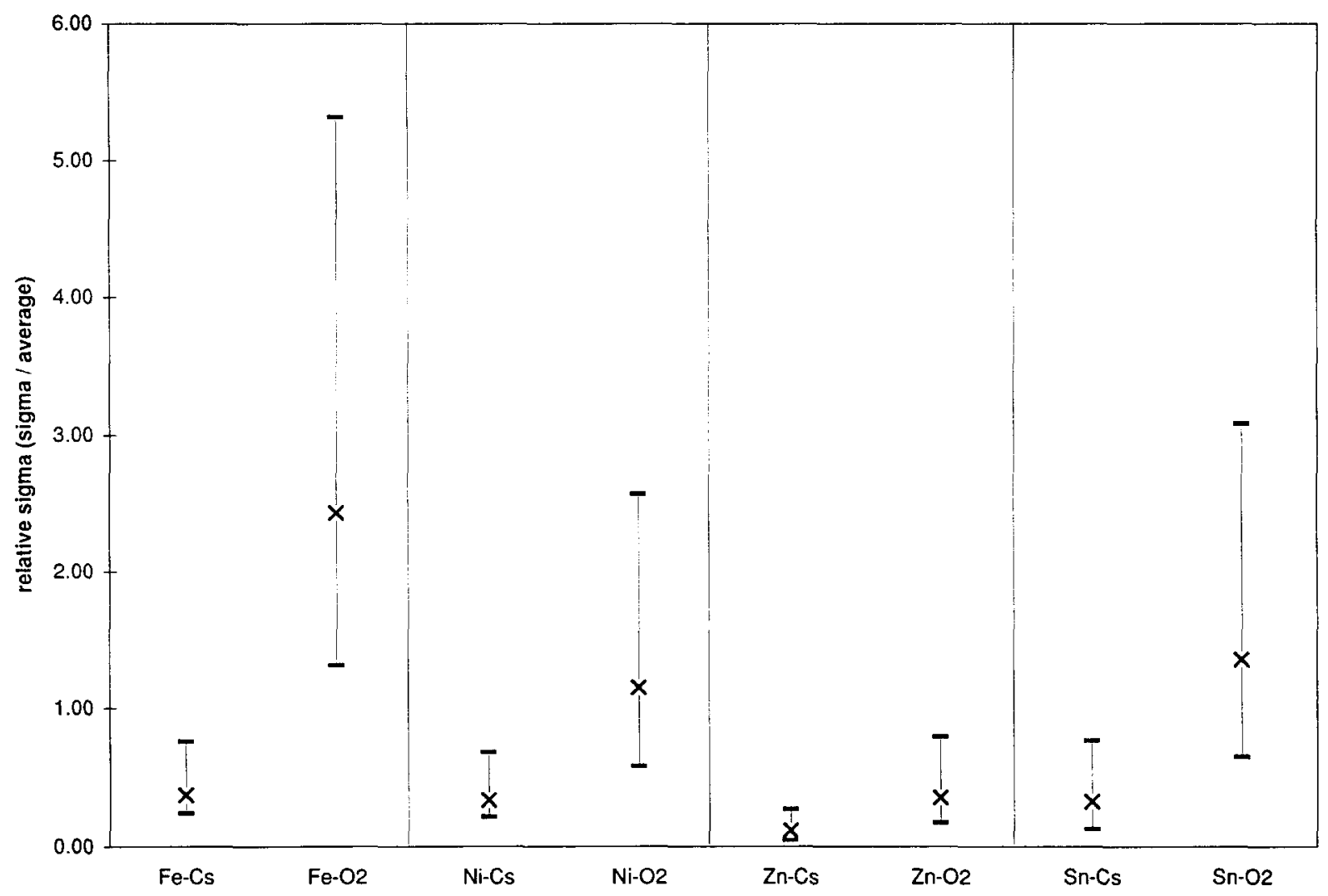

Fig. 1. Estimated relative sigmas due to sample variation and their confidence intervals.

impurity elements $(\mathrm{Fe}, \mathrm{Ni}, \mathrm{Sn})$ is significantly larger than the critical $F$-value at the 5\% significance level (1.63). This indicates that the acquisition of $\mathrm{CsM}^{+}$clusters enables us to obtain relative sensitivity factors that are more reproducible than in the case of the acquisition of the more commonly used $\mathrm{M}^{+}$ ion intensities. For the matrix element, $\mathrm{Zn}$, the variance ratio is smaller than the critical $F$-value, which implies that the total variation of the relative sensitivity factors has not significantly improved for the cesium analyses.

In a second step, it is the intention to examine how much of this overall variation is due to the contribution of the variation in sample composition, represented by each SRM. In other words, what is the influence of matrix effects upon the relative sensitivity factors for $\mathrm{CsM}^{+}$and $\mathrm{M}^{+}$ions? A one-way analysis of variance (ANOVA) is therefore performed to separate and estimate the source of variation, being the matrix (represented by each SRM). As the null hypothesis, it is assumed that there is no variation between the relative sensitivity factors for different samples rather than a random one. A total of eight ANOVAs are performed: one for each of the four elements and each of the two analysis conditions. Each data set for each ANOVA consists of 45 values (nine results for each of the five SRM samples). The results of all eight ANOVAs are summarized in Table 4. From left to right the columns in Table 4 represent the number of the analysis of variance (column 1), the element (column 2) and the analysis condition (column 3), and the sources of variation (column 4): these have been separated into a variance between SRM 
samples and a variance within SRM samples. The sum of squares, the degrees of freedom and the mean square, results of the ANOVAs [10] are listed in columns 5-7 for each source of variation. Columns 8 and 9 list the calculated $F$-ratio $[10]$ and the critical $F$-value. These two columns demonstrate that the null hypothesis is most likely not true: the value for the $F$-ratio is larger than the critical value, in all cases, which means that a significant difference can be seen between the various relative sensitivity factors measured for the different samples, not explicable by a mere random variation.

From each of the eight ANOVAs, the variance which describes the difference between relative sensitivity factors due to different samples and its confidence limits can be estimated [10]. These (relative) values are plotted for each of the elements and conditions in Fig. 1. It can be observed that $\sigma_{\mathrm{R}}\left(\mathrm{O}_{2}^{+}\right)>\sigma_{\mathrm{R}}\left(\mathrm{Cs}^{+}\right)$for all elements (marked $\times$ in Fig. 1), indicating that the influence of matrix effects upon relative sensitivity factors is indeed smaller in the case of cesium clusters. However, since the confidence intervals for the two analysis conditions overlap each other, the difference in variance is not statistically significant and more experiments will be needed in this area to obtain a decisive answer. Primarily, it will be necessary to improve the reproducibility in determining the relative sensitivity factors, and hence to search for potential sources of variation when analyzing a single sample.

\section{Conclusions}

The results of this study show that matrix effects influence the determination of the relative sensitivity factors for the acquisition of both cesium clusters $\left(\mathrm{CsM}^{+}\right)$and regular $\mathrm{M}^{+}$ ions. The data of the present study suggest that the influence has been reduced to a certain extent for cesium clusters. These data, however, are not altogether conclusive, since the variances between samples for cesium and oxygen measurements are not significantly different from each other and more experiments are required in order to obtain more decisive results. In particular, the reproducibility of the measurements within one sample group needs to be improved. The present results have shown that this is quite low. Improvements are already seen for cesium clusters, but they are not yet satisfactory.

\section{Acknowledgments}

A.A. is a research associate at NFWO/ FNRS, Belgium. This text presents research results of FKFO/IIKW and the Belgian program on Interuniversity Attraction Poles initiated by the Belgian State, Prime Minister's Office, Science Policy Programming.

\section{References}

[1] H. Werner, in L. Fiermans, J. Vennik and W. Dekeyzer (Eds.), Electron and Ion Spectroscopy for Solids, Plenum, New York, 1978.

[2] A. Benninghoven, F.G. Rüdenauer and H.W. Werner, Secondary Ion Mass Spectrometry. Basic Concepts, Instrumental Aspects, Applications and Trends, Wiley, New York, 1987

[3] P. Williams and L. Streit, Nucl. Instrum. Methods Phys. Res. B, 15 (1986) 159-164.

[4] Y. Gao, J. Appl. Phys., 64(9) (1988) 3760-3762.

[5] C.W. Magee, W.L. Harrington and E.M. Botnick, Int. J. Mass Spectrom. Ion Processes, 103 (1988) 45-56.

[6] M.A. Ray, J.E. Baker, C.M. Loxton and J.E. Greene, J. Vac. Sci. Technol. A, 6(1) (1988) 44-50.

[7] Y. Gao, Y. Marie, F. Saldie and H.N. Migeon, in A. Benninghoven, Y. Nihei, R. Shimizu and H.W. Werner (Eds.), Secondary Ion Mass Spectrometry SIMS IX, Wiley, Chichester, 1994, pp. 382-385.

[8] Y. Gao, in A. Benninghoven, C.A. Evans, K.D. McKeegan, H.A. Storms and H.W. Werner (Eds.), Secondary Ion Mass Spectrometry SIMS VII, Wiley, Chichester, 1990, pp. 155-158.

[9] H. Gnaser and H. Oechnsner, Fresenius' J. Anal. Chem., 341 (1991) 54-56.

[10] O.L. Davies and P.L. Goldsmith, Statistical Methods in Research and Production, Longman Scientific and Technical, Essex, 1988. 